\title{
Resource-efficient human capital use in the context of technological changes and sustainable development
}

\author{
Iuner Kapkaev ${ }^{1, *}$ and Daria Rudenko ${ }^{1}$ \\ ${ }^{1}$ Chelyabinsk State University, 129, Bratiev Kashirinykh str., 454001, Chelyabinsk, Russia
}

\begin{abstract}
Technological modernization requires a cautious approach on the state and business to the conditions for high-quality human capital formation. Ensuring competitiveness is possible only under the condition of a systematic and strategic approach to investment in human capital. In the study, human capital is presented as a resource that becomes a priority. The analysis of resources through potential, a development means with no material form, seems the most promising. Digital transformation is making a significant contribution to productivity growth. To ensure high competitiveness, it is necessary to change the organization's culture. limportant condition for productivity growth is satisfaction and motivation. The article shows that the primary source of surplus-value is employees' qualifications, professionalism, and creativity. The paper explored increasing possibilities of leaving routine operations in the field of robotization, both for physical robots and software bots. It was revealed that the need to reveal the creative and creative potential of a person increases many times over. Particular attention is paid to the conditions prevailing in 2020, which made it possible to leap forward in the field of remote work and distance education.
\end{abstract}

\section{Introduction}

The priority area of the Russian economy's socio-economic development is technological modernization, as well as the accumulation and development of human capital at the national level. Over the past decades, projects have been actively developing in Russia to create an innovative infrastructure of technological competencies. These include centers for fundamental and applied research, research organizations, scienceintensive industrial enterprises. Particular attention is paid to investing in human capital to achieve its high quality at all levels [1]. Over the years, scientists and researchers in labor economics have consistently proven that human capital plays an essential role in ensuring any company's competitiveness. Employees possessing a high level of knowledge, experience, competencies, professionalism will always be in demand in the market and highly appreciated. Thus, the most important Russian research task is to assess the trends

\footnotetext{
* Corresponding author: zam@csu.ru
} 
and effectiveness of the accumulation of human capital required for the implementation of technological modernization [2].

The efficient use of resources is a necessary factor in forming the competitiveness of any economic system. In any company, the driving force is a person who can acquire high professional knowledge and apply it effectively in various fields of activity. Correct management and use of labor resources is the key to the company's success [3]. The study of issues related to the concept of "resources" was studied by various domestic and foreign authors.

In the modern system of economic relations, the role of a person is improving and changing. The employee is considered as a resource of the company; its qualifications, experience, and knowledge are essential. Professional growth in the form of continuous professional development, training unlocks the potential of human capital. According to R.L. Dafta, firm resources represent assets, information, knowledge, and other firm attributes that improve target and resource efficiency. R.L. Ackoff summarizes that a limited resource ceases to be such if the demand for it decreases. L.G. Hams represents resources through potential. To achieve these goals, the availability of resources allows having potential opportunities. I.L. Bachilo designates the concept of resources as a systemforming element of concrete human activity organization [4].

Initially, the term resources meant all the means and capabilities of the company, which are aimed at development in general, and they were measured in material form. In changing economic conditions, the use of digitalization, the introduction of information and telecommunication technologies, the main form of resources in a company is becoming intangible, namely a person. Therefore, it is essential to pay attention first of all to human capital.

\section{Materials and methods}

In the digital age, economic relations have transformed in all spheres of society. The use and application of digital technologies is reflected in increasing the productivity of human capital. Digital transformation is present in all aspects of business activity, which requires dramatic changes in technology, culture, new products, and services. The critical stages of digital transformation include taking into account all the business needs of the company. To keep up with the times, firms need to move away from outdated technologies and change the organization's culture, supporting the acceleration of processes. The development of the company takes place with constant investment in personnel through training and development. With the effective use of all interrelated elements, the company remains developing, prosperous and competitive on the market [5]. The key stages of digital transformation are depicted in Figure 1. 


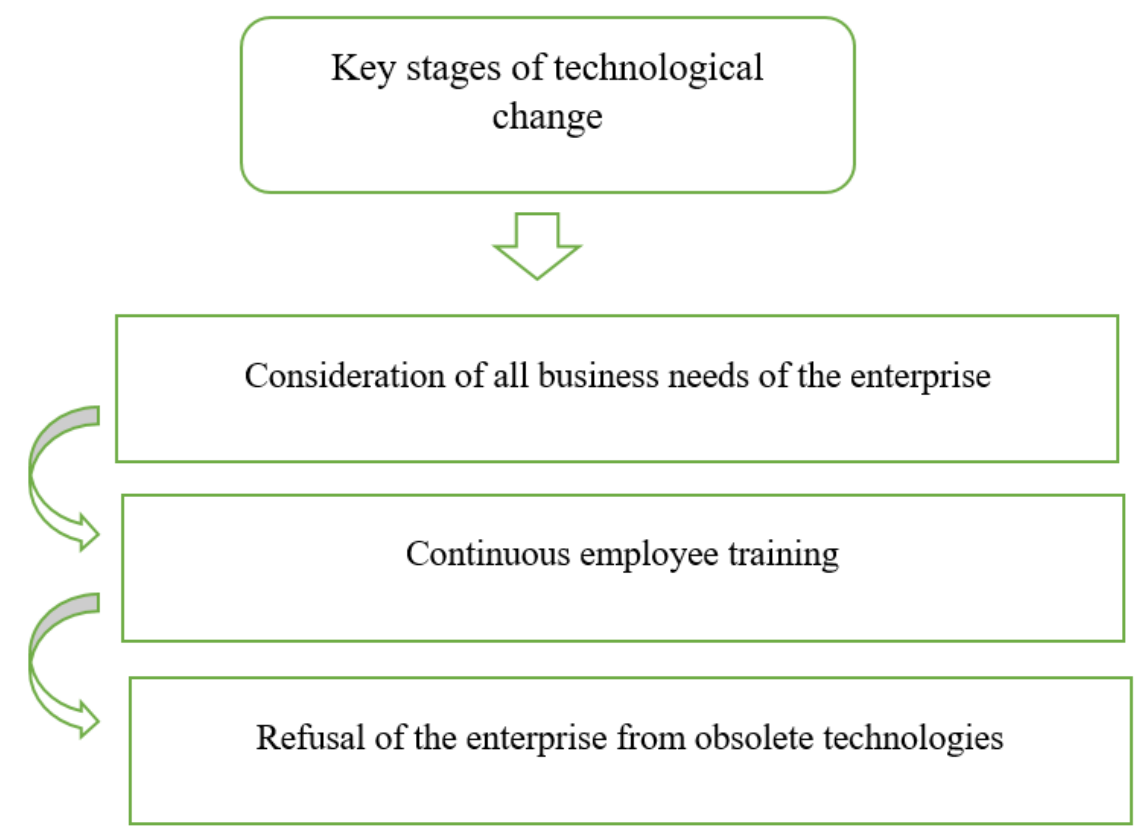

Fig. 1. Key stages of technological change.

At the post-industrial stage, the formation of human capital has an increasing impact on the company's success. Many scientists, economists have used different approaches to the study of this concept. Since the 18th century, the theory of human capital has been considered by such classical economists as D. Ricardo, A. Smith, L. Walras, A. Marshall and others. At the beginning of the 20th century, the scientific works of F. Taylor contributed to the development of the theory of human capital. The economist pointed to labor efficiency management. E. Mayo determined the relationship between productivity and job satisfaction. In the 70s. XX century scientists D. McGregor, F. Herzenberg defined man's role in the production system and paid special attention to motivation, incentives, and strategies for personnel management. T. Schultz, G. Becker made an outstanding contribution to the formation of the theory of human capital. Economists pointed to the totality of acquired and innate abilities that increase a person's income and an enterprise as a whole. Initially, human capital management was considered as the management of the company's resources [6].

Today, the company's success is based not only on classical material and intangible resources, raw materials, technologies but mainly on the surplus value created with creative, highly developed, and experienced employees. The strategic approach to enterprise management is based on the development of human capital. Its role is constantly growing in the digital economy. The development of human capital is influenced by the size and scope of the enterprise, development strategy, organizational culture, stage of the life cycle, innovations, and various technologies. The primary source of surplus-value are people with professional experience, knowledge, and high qualifications. To support the key stages of digital transformation in the modern economy, it is necessary to focus on the development of human resources. Therefore, it is important to invest in human capital development, which allows achieving competitive advantages in the market through innovative implementations and training [7]. 


\section{Results}

A company's development is not enough to perform management and production functions; it is necessary to improve and introduce innovations constantly. Physical labor is more and more replaced by robotization every day; therefore, a significant proportion of human labor prevails in intellectual activity. With such changes, employees become professionals in their field, gain production experience, possess knowledge and information. The geographical boundaries of attracting workers are expanding due to the expansion of mobility, including new forms of attraction. Human capital, which would have received its development in the learning process, brings its owner an additional income and a highpaying job, the opportunity to take a prestigious position [8]. The creation of a high-tech workplace is an important condition for implementing the employee's personal achievements.

The digital economy was gradually introduced into all technological processes of the enterprise. The global pandemic caused by the coronavirus infection in 2020 has hit the global economy. The closure of countries, the interruption of supplies, and quarantine measures forced many companies that operated offline to change their work format. To stay on the market, it was necessary to find ways to exit in the shortest possible time. However, the pandemic has given rise to a dramatic increase in the use of digital space. Businesses around the world have become more flexible, quickly adapting to new conditions [9].

However, when switching to remote work, many employees faced problems, especially in implementing work at home. Many employees had an uncertain work situation related to the timing of remote work and the very essence of work activities. It was necessary to master new work programs to interact with employees and clients online in the shortest possible time. Many have faced difficulties in their work due to misunderstanding and ignorance of their remote work. Therefore, many managers solved these problems with their employees' training and professional development [10].

Having worked at home during 2020, many employees were ready to go back to the office since there was no personal and workspace. It is comfortable to work outside the home for many, communicating with employees and clients in person. However, other employees are willing to work at home. An essential thing in remote work is selforganization and self-study.

If we consider the data for 2019 on remote work and work in the office and compare with 2020 , then the percentage of remote work increased by $50 \%$ and work in the office decreased by $28 \%$. The considerable growth in remote work has been caused by the global pandemic, which has made its own adjustments to the work processes in many market areas. Figure 1 shows the data as a percentage between remote work and office work for 2019 and 2020 [11]. 


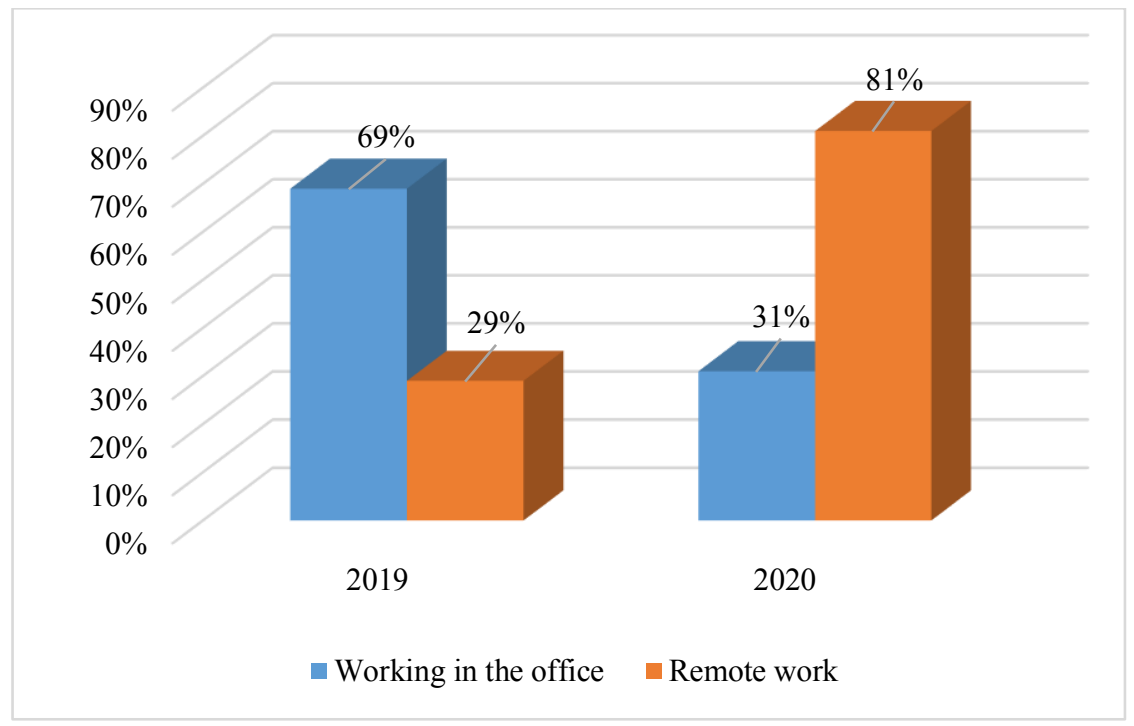

Fig. 2. Remote work and work in the office proportion for 2019-2020 in Russia.

With the development of remote work in the market, many platforms are formed to carry out work. Application of various applications that allow you to interact with colleagues and clients in a remote format.

In Russia, the material and technical base for the implementation of the digital economy is well developed. In addition to business development, the state also does not stand still but develops for citizens. The coronavirus epidemic has become an impetus for accelerated digitization. The most popular professions that are introduced and adapted for remote work in 2020 are the following: IT professions, marketing and sales, design, system administrator and others. The figure shows the demanded professions of remote work in 2020 [11].

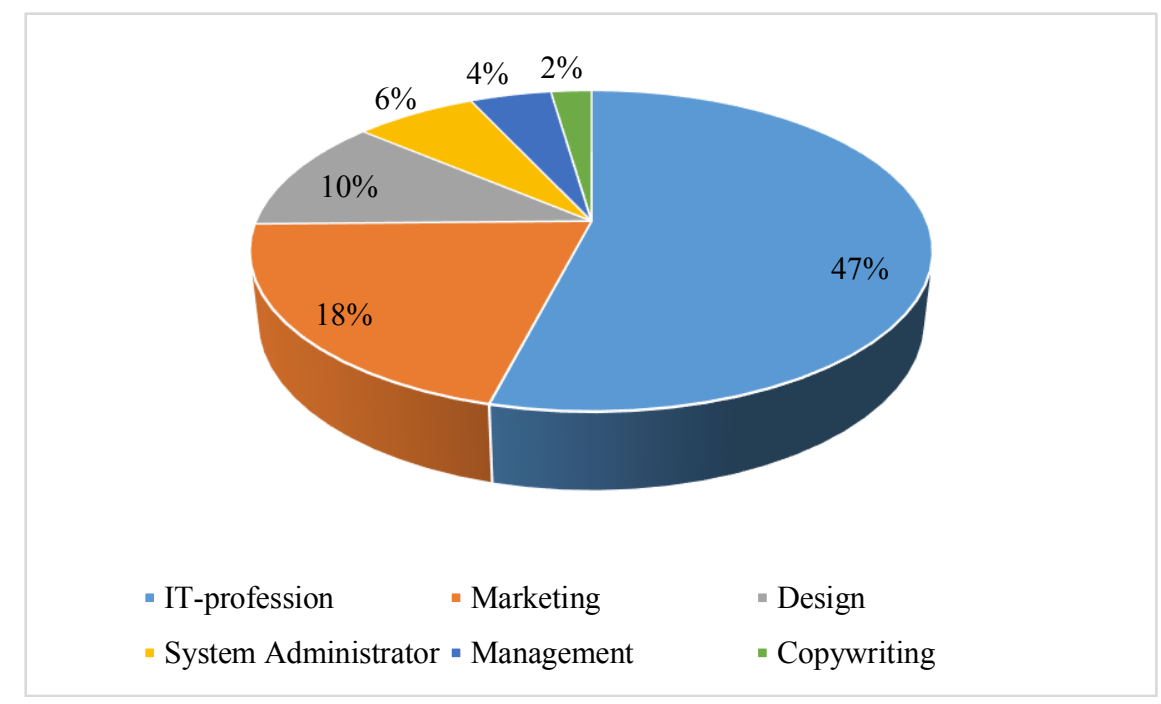

Fig. 3. The most popular remote work professions in 2020 in Russia.

At the state level, Internet platforms are being formed, with the help of which you do not need to stand in queues for several hours, get a service at the appointed time and day. Most operations can be done through one digital field. An example is the Gosuslugi 
platform. Many operations can be performed in single window mode. All this ensures an increase in the quality of life, which is reflected in labor productivity growth.

The resulting digital environment makes it possible to move to a new type of work remote work. Labor legislation is being modernized, providing increased opportunities for both the employee and the employer. The emerging trend is optimizing office costs and productivity growth associated with flexible working hours [12].

The transition to remote work provides a person with the opportunity to earn money anywhere in the world, regardless of social status, health, education. For people with disabilities, retirees, students, parents caring for a child, an abundance of vacancies is provided, taking into account the form of employment, interests and level of qualifications.

During the pandemic, the delivery sphere acquired an explosive development. Using the application, you can order the delivery of food, food, clothing, medicines, and correspondence without leaving home. Remote work has also become very popular. The development of the market for user devices, applications, and cloud technologies provides the widest possible opportunities for remote work, having a personal computer or laptop, and a tablet. Remote work covers more and more different areas of activity. In the banking sector, one can cite the Tinkoff Bank online bank's example, which is the most popular among the population among private banks in Russia. All transactions take place online, and the cards are delivered to home. In the field of information technology, Yandex is the leading company in Russia, offering more and more different services. Thanks to remote work, an employee can adjust work schedule. Moreover, work in several companies and get more income. Ample opportunities are provided for the implementation of their work activities in any city. Living in Chelyabinsk, employee can work remotely in St. Petersburg. Russia's territory is vast, so time zones change very often. Chronologically, it is convenient when the main office is located in Moscow, and the employee operates in Vladivostok. Thus, with the help of employees, the company always remains in touch and can provide its services at any time. Also, the positive aspect of remote work can be noted the savings in the enterprise. When employees are remotely accessible, maintenance and rental costs are reduced. Managers can communicate with employees via video communication, hold meetings and monitor the progress of work online.

With each passing day, more and more businesses are moving digital and working remotely. Of course, the transition to digitalization requires colossal efforts and investments. However, for companies that hold and claim to maintain leading positions, it is necessary to make every effort.

The development of HR technologies in using human capital is not limited to the use of information and telecommunication technologies; ethical marketing in the field of work with personnel is a promising direction for the effective use of labor. White metallurgy is a striking example. The philosophy of white metallurgy is based on environmental friendliness, smart technologies, customer focus, and comfortable working conditions for employees. The working area has been transformed into spacious and bright rooms with the latest automated equipment. The workers' work uniform concept changed from dark colors to white and bright ones, forming an appropriate attitude towards life and work. Thus, among other things, the issue of attracting young personnel is being resolved. Besides, by concluding contracts with a training organization, the white metallurgy provides itself with a staff of highly qualified employees for the future. Based on the European dual system, we have developed our training program, which devotes more time to practical training. Thanks to this approach, employees develop innovative knowledge and a desire to progress.

However, in the transition to a digital environment, not everyone can adapt to changing market conditions. To move the company forward, it needs people who understand how to use new technologies. Entrepreneurs can protect a business from crises by introducing complete digitalization at all possible stages of business processes, automating production 
using new technologies, using modern integral sales platforms. The model of a modern sustainable business will depend on all interconnected elements' totality, which will be led by human capital. Therefore, an essential point of a successful company is constant investment in human resources. Investing can manifest itself directly through ongoing employee training and development. Thanks to increased knowledge, workers can always be competent in their work issues, adapted to rapidly changing conditions and demand in the labor market [13].

\section{Discussion and Conclusion}

With the advent of new technologies, robotization of production processes, human capital requirements are changing. A modern competitive employee must have the following characteristics: quick adaptation to new conditions, involvement in the work process, learning ability, and working with digital platforms. In a digital economy, it is essential to develop human capital through innovative approaches and new views. To improve the constant level of knowledge of your employees, it is necessary to resort to training. With help, digital opportunities and distance education. The learning process can take place on the job. Thus, the employer saves money on business trips, the work process does not stop, and the employee saves his time and receives additional knowledge in the form he needs, instantly applies it in practice.

Thus, the formation of human capital in modern conditions should be based on development and investment. Any company's active force is a person with professional knowledge, potential, creativity, and mobility concerning changing conditions. This had a significant impact on the conditions for the development and use of human capital. The platform economy allows the use of human capital on a fundamentally new basis. Relevant recruitment of small contractors for short-term work ensures the rational use and growth of the welfare of a large number of unclaimed labor.

\section{References}

1. Y. Doroshenko, I. Malykhina, I. Somina, Economy of Region 16(4), 1318-1334 (2020) DOI: 10.17059/EKON.REG.2020-4-21

2. M. Zeebaree, G. Ismael, O. Nakshabandi, S. Sattar, M. Aqel, Estudios de Economia Aplicada 38(4), (2021) DOI: 10.25115/eea.v38i3\%20(1).3970

3. S. Jones, Oxford Bulletin of Economics and Statistics 82(6), 1429-1455 (2021) DOI: $10.1111 /$ obes. 12374

4. B. White, European Journal of Development Research 33(1), 54-70 (2021) DOI: 10.1057/s41287-020-00300-0

5. A. Popova, S. Gorokhova, M. Abramova, I. Balashkina, Studies in Systems, Decision and Control 314, 89-96 (2021) DOI: 10.1007/978-3-030-56433-9_11

6. N. Konno, C. Schillaci, Journal of Intellectual Capital (2021) DOI: 10.1108/JIC-022020-0060

7. I. Kapkaev, I. Nurmukhametov, Smart Innovation, Systems and Technologies 138, 367-380 (2020) DOI: 10.1007/978-3-030-15577-3_36

8. C. Btuşaru, I. Sbârcea, Studies in Business and Economics 15(2), 28-45 (2020) DOI: 10.2478/sbe-2020-0023

9. D. Chiaroni, P. Vecchio, D. Peck, A. Urbinati, D. Vrontis, Resources, Conservation and Recycling 168 (2021) DOI: 10.1016/j.resconrec.2020.105286 
10. M. Jamal, I. Anwar, N. Khan, I. Saleem, Asia-Pacific Journal of Business Administration (2021) DOI: 10.1108/APJBA-05-2020-0149

11. https://rosstat.gov.ru/

12. N. Petrov, Lecture Notes in Networks and Systems 160, 708-712 (2020) DOI: 10.1007/978-3-030-60929-0_91

13. Y. Vlasenko, O. Okhrimenko, L. Shmorgun, et al, International Journal of Management, 11(2), 95-104, (2020). DOI: 10.34218/IJM.11.2.2020.010 